\title{
Faculty Observables and Self-Reported Responsiveness to Academic Dishonesty
}

\author{
Robert T. Burrus, Jr., Ph.D. \\ Adam T. Jones, Ph.D. \\ William H. Sackley, Ph.D. \\ Michael Walker, Ph.D. \\ University of North Carolina, Wilmington
}

\begin{abstract}
Prior to 2009, a mid-sized public institution in the southeast had a faculty-driven honor policy characterized by little education about the policy and no tracking of repeat offenders. An updated code, implemented in August of 2009, required that students sign an honor pledge, created a formal student honor board, and developed a process to track and hold accountable, repeat offenders. Self-reported data on faculty vigilance to detect and punish cheating is collected both prior to and after a change in the honor code at a mid-sized public institution in the southeast. We find that, at the time of the first survey, full professors and faculty with a longer duration of employment were more likely to claim vigilance in cheating detection and harshness in punishing cheaters than newer, untenured faculty. The relationship between these factors and detection and harshness diminished when the honor code was enhanced.
\end{abstract}

Keywords: academic honesty, faculty, administration, honor code

T he cheating epidemic in universities across the world is well documented, with recent research taking the problem as given and examining factors that contribute to cheating or whether the problem is getting worse. In the effort to develop policies to prevent student cheating, many studies have focused on factors correlated with academic dishonesty. These factors broadly include individual student characteristics (age, gender, grade-point average, and membership in a fraternity or sorority), perceptions about the cheating of peers, whether professors are clear in defining cheating, and perceptions about the likelihood of being caught for cheating and the severity of penalties if caught. The research presented in this article contributes to the literature by focusing on changes in faculty vigilance and attitudes, rather than focusing on students, following the imposition of an honor code.

While there is a growing consensus that cheating is a problem on academic campuses, the more difficult as well as more interesting topics may be causes and prevention methods. In general, students and faculty have substantially similar views of what is considered cheating. Roig and Ballew (1994) find that 
student perceptions of what faculty consider cheating match faculty views relatively closely, while faculty tend to overestimate students' tolerance of academic dishonesty. However, it should be noted that students' perceptions of professors' tolerance correlates with their own tolerance. This could be students projecting their views onto faculty, or students may be taking cues from faculty members. To the extent that it is the latter, further research on faculty attitudes is warranted. The research presented below examines the relationship between self-reported faculty vigilance in detecting and punishing cheating and observable faculty characteristics.

\section{Cheating Definitions and Demographics}

Graham et al. (1994) compared survey data of students from a private Catholic college and a community college to that of faculty at the Catholic college and found agreement between students and faculty about the most egregious infractions. However, a much smaller percentage of students believed behaviors that were helping others, such as providing information about a test or allowing someone to copy homework, constituted cheating. There was also disagreement about using an old test to study without the teacher's knowledge or submitting a paper for more than one class. Exploring the more ambiguous behaviors, Higbee and Thomas (2002) surveyed students and faculty and found that student and faculty views are similar but there is considerable disagreement within each group. Burrus, McGoldrick, and Schuhmann (2007) showed that providing a definition of cheating increases the number of incidents self-reported by students. Their result implies that the set of behaviors considered cheating is not universal. ${ }^{i}$ Even if the dichotomous definitions of cheating were the same, Roth and McCabe (1995) showed that agreement on the severity of infractions, as judged by penalties suggested, is lacking.

In addition to the focus on definitions of cheating, there is a healthy literature on student- specific characteristics and situational factors that contribute to cheating. One such factor is students' perception or experience with others cheating. .i O'Rourke et al. (2010) suggested that when viewed as a social behavior, the knowledge, suspicion, or direct observation of peers cheating may have an important effect on students' behavior. In fact, they found that when presented with a vignette including peer cheating, students' responses regarding their own anticipated behavior is only moderated by latent attitudes. This finding emphasizes the importance of a culture of honesty and creating a negative-feedback loop instead of defaulting to the positive-feedback loop prevalent on academic campuses. By default, responsibility for clearly communicating a definition of acceptable and unacceptable behavior falls to the individual faculty member. Parameswaran (2007) went as far as to state that faculty members have a responsibility to prevent cheating and faculty who "allow" dishonesty are morally responsible for it.

\section{Prevention}

Having established that academic dishonesty is a problem, the literature also investigates techniques for prevention. Much of the literature views academic dishonesty as analogous to crime and is based on Becker's (1968) seminal work modeling the supply of crime as a function of probability of conviction and the likely punishment once convicted, sometimes also referred to as certainty and severity of punishment respectively. Doob and Webster (2003) provided a review of the crime literature and found 
that the response to severity of punishment is almost non-existent; yet most researchers are hesitant to accept the finding. Doob and Webster's findings are consistent with other reviews such as Paternoster's (1987). This suggestion is supported by Barnard-Brak, Schmidt, and Wei (2013) who used experimental style survey data varying the penalty for infraction and found that being reported to an honor board may not have any deterrent effect beyond that of a verbal reprimand and grade penalty. While there is some work suggesting severity (or its perception) of penalties deters cheating, such as Burrus et al. (2013), LaSalle (2009), Mixon (1996), etc., there are also studies that found severity of penalties to be positively related to cheating and suggest there are potential endogeneity problems in such variables (McCabe \& Trevino, 1993). In addition, many studies found the probability of punishment is much more important than severity, such as McCabe and Trevino (1993) or Nagin and Pogarsky (2003) to cite only two.

While the literature on strategies to prevent cheating is fairly significant, the literature regarding tactics remains relatively thin. One notable exception is Hollinger and Lanza-Kaduce (2009) who found both cheaters and non-cheaters believe question scrambling to be an effective cheating-reduction tactic. In addition, cheaters believe the use of study sheets and passing out old exams to be a more effective deterrent than non-cheaters believe. This result is consistent with the literature that suggests the perception that others are cheating or have some advantage contributes to the likelihood of cheating; by leveling the playing field and being clear about the expectations, faculty make cheating less tempting. The most effective countermeasure may be to build up and tap into student morals and integrity. Ogilvie and Stewart (2010) and Cochran et al. (1999) suggested that student attitudes - especially shame - are the most important deterrents. Their findings, combined with the ineffectiveness of administrative punishments, suggest that the role of faculty and administrators may be to promote a culture of integrity, dialogue with the students, and encourage students to take an active role in policing their peers.

If, as is often suggested by the cheating and crime literature, it is certainty of punishment that deters cheating and crime, then the policy prescription is to increase vigilance and follow up on allegations of cheating. Thus, one component of increasing the certainty of punishment is to encourage and facilitate peer reporting. Unfortunately, many students are hesitant to report their peers. Nuss (1984) suggested that only $3 \%$ of students would report their peers for any infraction and slightly more than a quarter of students would report peers for serious infractions unless required to report by the university. In the case of required reporting, those who would report "any infraction" increases to 15\%, and 28\% would report if they believed the infraction to be "serious." Sierles, Kushner, and Krause (1988) reported that only $13 \%$ of cheaters will anonymously self-report cheating on unproctored behavioral-science exams, and their findings are considerably higher than Burton and Near (1995), who put the percentage in the three to four percent range!

Rennie and Crosby (2002) put the percentage of students willing to report peers at 13\%; but they also suggested some reasons why peers would or would not report. Reasons not to report their peers included camaraderie, fear of retaliation, cheating as the accepted norm, and perception that policing cheating is someone else's responsibility. Students also indicated that a lack of guidelines, high evidentiary requirements, uncertainty about what is considered cheating, and a poor administrative record on follow-through discourage reporting. Reasons for reporting include avoiding negative 
consequences for themselves or others, maintaining standards and integrity, getting violators the help they need, and satisfying the desire for vengeance. Jenkel and Haen (2012) suggested that one way to encourage reporting is to make sure students understand how cheating by their peers affects their own grade. They also suggested a reporting system must maintain anonymity in order to reduce social costs and fear of reprisal.

\section{Honor Codes}

The varied findings across the research regarding certainty and severity of punishment, peer reporting, student attitudes, etc., suggest that reducing cheating is more about cultural change than simply a tweak to administrative policies. McCabe and Trevino (1993) suggested universities that employ "traditional" honor codes typically have decreased self-reports of cheating. These traditional codes are characterized by unproctored exams, an honor pledge, the encouragement or requirement of student reporting of cheating, and student-run honor boards. These campuses generally have higher levels of peer reporting of cheating (McCabe, Trevino, \& Butterfield, 2001). Yet Vandehey, Diekhoff, and LaBeff (2007) reported no change in students' self-reporting of cheating following the imposition of an honor code, and they found non-cheaters are much more supportive of the honor code than cheaters. Thus, a change in policy alone may not have an effect. Furthermore, relying solely on students to police cheating may conflict with other university goals. Gallant (2007) pointed out that relationships, community, and group learning may conflict with integrity and peer reporting. In promoting a culture of honesty, there is a role for students, faculty, and administrators, as suggested in Whitley and Keith-Spiegel (2001), in emphasizing its importance as well as maintaining that focus over time in order to change and/or maintain the culture.

Most universities (especially large ones) do not use traditional honor codes. This leaves the faculty (and administrators) on the front-lines against academic dishonesty at universities without traditional honor codes. Unfortunately, as Staats et al. (2009) suggested, even faculty avoid cheating confrontations, often due to lack of evidence. Coren (2011) noted that faculty avoidance could be rationalized behavior to avoid uncomfortable, confrontational situations, and Roig and Ballew (1994) suggested that students become more tolerant of academic dishonesty when faculty members avoid confrontations.

This increase in tolerance brings the role of honor codes and policies full-circle. Traditional honor codes rely on pledges and peer policing, which may be lax, and honor policies rely on policies set forth by the university to which much of the cheating may be unobservable. Many universities have adopted modified honor codes that retain both faculty and student involvement. These efforts may help to create a culture of honesty among the students, as suggested by McCabe and Trevino (1997), and an environment in which faculty persons believe that they are united against cheating.

While there is a rich and growing literature examining factors that impact student cheating, the analysis of professorial attitudes toward cheating and activities to combat cheating is relatively thin. If the weakness of a traditional honor code is that it relies on students and culture, the weakness of honor policies is that they rely on faculty members who very well may have other priorities, such as research. However, many large institutions use a modified honor-code allocating responsibility to both faculty and students. This suggests the role of the faculty is to motivate students to learn and master material, as 
well as continue to emphasize the importance of academic honesty and integrity. This paper seeks to determine the factors that relate to increased faculty policing of cheating at a regional, public university in the Southeast.

\section{DATA}

In the Fall of 2008, the mid-sized public institution in the southeast conducted an on-line survey of both students and faculty. These initial, anonymous surveys were administered to 5,000 students and all faculty persons during February of 2009. Following a change from an honor policy to a modified honor code, a similar survey was also conducted in 2011.

The new, modified code, which took effect in August of 2009, is somewhere between the old policy and a traditional honor code. The modified code gave faculty the ability to sentence students on their first cheating offence, with an accompanying letter of responsibility placed in the student's academic file in the Dean of Student's Office. If the student cheated thereafter, the case automatically went before an honor board consisting of four students and two faculty members. The recommended punishment for a repeat offender is a one-semester suspension. In addition to the student-led honor board, students now sign an honor pledge when they arrive on campus and continue to be encouraged to report witnessed infractions. Both students and faculty are supposed to be educated about the honor code each year, and the honor code statement appears on nearly every syllabus.

Both faculty surveys had, approximately, a one-third response rate. Faculty members were asked to indicate which behaviors they considered cheating from a list of eighteen (see Table 1). In the two years after the new code was adopted, there was an increase in the proportion of faculty who believed that the listed behaviors constituted cheating in fourteen of the eighteen cases. However, asking for help from a classmate on the assigned homework, paper, or project was the only behavior that drew a statistically significant increase in the proportion of faculty listing the behavior as cheating. (Notably, asking a classmate a question about a take-home exam was significant at the $11 \%$ level.) A lower proportion of faculty reported considering the following as cheating behaviors: adding to one's bibliography unread sources, poor citations, visiting a professor to influence grades, and using a cheat sheet. The only statistically significant decrease, however, was in the case of using unread sources in $a$ bibliography. This behavior was not specifically outlawed in the new code.

Faculty members were also asked about their university demographics and about the certainty and severity of punishment in their classes. Variable descriptions of these data are provided in Table 2 with descriptive statistics provided in Table 3. Using the data acquired from Table 1, the variable Considered Cheating is the average number of behaviors that a faculty person considered to be cheating (from the list of eighteen). We note some long tails to the distribution as some faculty members believed that only a single action was cheating, while others believed that almost all the listed actions constituted cheating. We also note that there was no statistical change in the average between the two surveys (pre-code average was 9.05, while post-code average was 9.26 behaviors). 
Table 1

Proportion [Prop.] Considering Behaviors to be Cheating

\begin{tabular}{|c|c|c|c|c|c|}
\hline Behavior & $\begin{array}{l}\text { Prop. } \\
\text { consider } \\
\text { cheating }\end{array}$ & S.D. & $\begin{array}{l}\text { Pre- } \\
\text { Code } \\
\text { Prop. }\end{array}$ & $\begin{array}{l}\text { Post- } \\
\text { Code } \\
\text { Prop. }\end{array}$ & $\begin{array}{l}\text { Prop. } \\
\text { test } \\
\text { P- } \\
\text { value }\end{array}$ \\
\hline $\begin{array}{l}\text { Asking for help from a classmate on the assigned } \\
\text { homework, paper, or project }\end{array}$ & .068 & .252 & .047 & .089 & $.086^{*}$ \\
\hline $\begin{array}{l}\text { Using a false excuse to get another exam date or to be } \\
\text { allowed to turn an assignment in past the due date }\end{array}$ & .808 & .394 & .803 & .813 & .788 \\
\hline $\begin{array}{l}\text { Writing formulas or other information on the back of an } \\
\text { exam as soon as it is received }\end{array}$ & .084 & .278 & .070 & .098 & .303 \\
\hline $\begin{array}{l}\text { Glancing at another student's test during the testing } \\
\text { period }\end{array}$ & .944 & .231 & .944 & .944 & 991 \\
\hline $\begin{array}{l}\text { Allowing another student to look on a test during the } \\
\text { testing period }\end{array}$ & .970 & .172 & .967 & .972 & .772 \\
\hline $\begin{array}{l}\text { Comparing homework answers with a classmate's prior } \\
\text { to class }\end{array}$ & .111 & .313 & .099 & .121 & .450 \\
\hline Asking a classmate a question about a take-home exam & .578 & .494 & .540 & 617 & .108 \\
\hline Using a test or quiz from a previous semester to study & .265 & .442 & .244 & .285 & .338 \\
\hline Having someone check over a paper before turning it in & .040 & .196 & .033 & .047 & .464 \\
\hline $\begin{array}{l}\text { Asking about the content of an exam from someone who } \\
\text { has taken it }\end{array}$ & .728 & .449 & 695 & .748 & .224 \\
\hline $\begin{array}{l}\text { Giving information about the content of an exam to } \\
\text { someone who has not yet taken it }\end{array}$ & .827 & .379 & .812 & .841 & .430 \\
\hline $\begin{array}{l}\text { Adding to one's bibliography citations that have not been } \\
\text { read so it appears more research has been conducted } \\
\text { than actually has }\end{array}$ & .728 & .445 & .770 & .687 & $.054^{*}$ \\
\hline Failing to properly cite another author's work & .867 & .341 & .873 & .860 & 683 \\
\hline Visiting a professor to influence a grade & .218 & .413 & .239 & .196 & .280 \\
\hline Using a cheat sheet during an exam & .939 & .239 & .948 & .930 & .425 \\
\hline $\begin{array}{l}\text { Having information programmed into a calculator during } \\
\text { an exam }\end{array}$ & .895 & .307 & .878 & .911 & .263 \\
\hline Studying with another student for an exam & .002 & .048 & 0 & .005 & .318 \\
\hline $\begin{array}{l}\text { Using only resources that confirm your point of view } \\
\text { when preparing a paper }\end{array}$ & .089 & .285 & .085 & .093 & .745 \\
\hline $\mathbf{N}$ & 427 & & 213 & 214 & \\
\hline
\end{tabular}

${ }^{*} p<0.1,{ }^{* *} p<0.05,{ }^{* * *} p<0.01$ 
Table 2

Variable Descriptions

\begin{tabular}{|c|c|c|}
\hline $\begin{array}{l}\text { Variable } \\
\text { Name }\end{array}$ & Type & Description \\
\hline $\begin{array}{l}\text { Considered } \\
\text { Cheating }\end{array}$ & Discrete & Number of items in Table 1 considered cheating \\
\hline Vigilance & Discrete & $\begin{array}{l}\text { Level of vigilance in detecting cheating [potential answers were very vigilant (4), } \\
\text { moderately vigilant (3), slightly vigilant (2), and not at all vigilant (1)] }\end{array}$ \\
\hline $\begin{array}{l}\text { Strict } \\
\text { Penalties }\end{array}$ & Discrete & $\begin{array}{l}\text { Self-reported strictness of penalties [potential answers were severe (4), moderate } \\
\text { (3), mild (2), and none (1)] }\end{array}$ \\
\hline Confront & Discrete & $\begin{array}{l}\text { Level of vigilance in confronting suspected cheaters [potential answers were very } \\
\text { vigilant (4), moderately vigilant (3), slightly vigilant (2), and not at all vigilant (1)] }\end{array}$ \\
\hline $\begin{array}{l}\text { Prevention } \\
\text { Index }\end{array}$ & Discrete & Considered Cheating $x$ Vigilance $x$ Strict Penalties $x$ Confront \\
\hline $\begin{array}{l}\text { Code on } \\
\text { Syllabus }\end{array}$ & Binary & Inclusion of a mention of honor code on syllabus \\
\hline Topics & Discrete & The number of examples or other honor-code topics on syllabus \\
\hline Discuss & Binary & Discusses honor code on first day of class \\
\hline Female & Binary & Indicates respondent is female \\
\hline Long tenure & Binary & At school longer than 6 years \\
\hline $\begin{array}{l}\text { Full } \\
\text { professor }\end{array}$ & Binary & Indicates respondent is a full professor \\
\hline $\begin{array}{l}\text { Associate } \\
\text { professor }\end{array}$ & Binary & Indicates respondent is an associate professor \\
\hline $\begin{array}{l}\text { Full time } \\
\text { lecturer }\end{array}$ & Binary & Indicates respondent is non-tenure track \\
\hline Business & Binary & Indicates faculty member is in Business school \\
\hline Nursing & Binary & Indicates faculty member is in Nursing School \\
\hline $\begin{array}{l}\text { Other } \\
\text { school }\end{array}$ & Binary & Indicates faculty member is in Education or Arts and Sciences \\
\hline
\end{tabular}


Table 3

Sample Statistics

\begin{tabular}{|c|c|c|c|c|c|c|c|}
\hline & \multicolumn{4}{|c|}{ Full Sample } & \multirow{2}{*}{$\frac{\text { Pre-Code }}{\text { Mean }}$} & \multirow{2}{*}{$\frac{\text { Post-Code }}{\text { Mean }}$} & \multirow{2}{*}{$\frac{\text { Means/Prop }}{\text { P-Value }}$} \\
\hline Variable & Mean & S.D. & Min & Max & & & \\
\hline $\begin{array}{l}\text { Considered } \\
\text { cheating }\end{array}$ & 9.15 & 2.29 & 1 & 16 & 9.05 & 9.26 & .344 \\
\hline Vigilance & 3.07 & .69 & 1 & 4 & 3.04 & 3.09 & .488 \\
\hline Strict penalties & 2.81 & .89 & 1 & 4 & 2.78 & 2.85 & .442 \\
\hline Confront & 3.28 & .77 & 1 & 4 & 3.24 & 3.31 & .323 \\
\hline Prevention index & 63.62 & 40.06 & 1.56 & 185 & 62.90 & 64.33 & .712 \\
\hline Code on syllabus & .90 & .29 & 0 & 1 & .88 & .93 & .135 \\
\hline Topics & 3.14 & 1.95 & 0 & 8 & 2.9 & 3.37 & $.013^{* *}$ \\
\hline Discuss & .81 & .39 & 0 & 1 & .78 & .84 & .167 \\
\hline Female & .48 & .50 & 0 & 1 & .42 & .53 & $.018^{* *}$ \\
\hline Long tenure & .52 & .50 & 0 & 1 & .51 & .54 & .469 \\
\hline Full professor & .25 & .43 & 0 & 1 & .26 & .24 & .634 \\
\hline Associate professor & .28 & .45 & 0 & 1 & .24 & .32 & $.071^{*}$ \\
\hline Full-time lecturer & .15 & .35 & 0 & 1 & .13 & .16 & .281 \\
\hline Business & .13 & .34 & 0 & 1 & .14 & .12 & .459 \\
\hline $\mathrm{N}$ & 427 & & & & 213 & 214 & \\
\hline
\end{tabular}

Note. ${ }^{*} p<0.1,{ }^{* *} p<0.05,{ }^{* * *} p<0.01$

Faculty members were also asked to describe the penalties they assigned for academic dishonestypotential answers were severe (coded as 4), moderate (3), mild (2), and none (1) - and how vigilant they are about detecting and confronting cheating-potential answers were very vigilant (coded as 4), moderately vigilant (3), slightly vigilant (2), and not at all vigilant (1). On average across both surveys, faculty consider themselves to be moderately vigilant in detecting cheating; the variable vigilant has a mean of 3.07. In addition, faculty self-report assigning moderately strict penalties and are moderately likely to confront observed cheaters. Though each of these variables increased after the new code was implemented, these increases were not statistically significant.

To ascertain a faculty member's overall efforts to prevent cheating, a prevention index was created by multiplying the considered cheating, vigilant, strict penalties, and confront variables. ${ }^{\text {iii }}$ To construct the 
index, considered cheating was rescaled, such that believing all 18 behaviors constituted cheating is scaled as a four; the rescaling helps to align the magnitude of this variable with others used to compute the index. Given variable coding, the prevention index can range from 0 to 256, depending on the how broad a faculty member's definition of cheating is, the strictness of his or her penalties, and how vigilant he or she is about detecting and confronting cheating. Across both surveys, the average prevention measure was 63.62, with a slight, but not statistically significant, increase in prevention after the adoption of the new code.

Faculty persons were queried about reminders they offer to students about the honor code in their courses. While the majority of professors provide an honor code statement on their syllabus, code on syllabus, and discuss the honor code on the first day of class, discuss, it is interesting to see the statistical increase in the attention given to specificity of honor code violations and other issues. In particular, faculty were asked about including each of eight topics on their syllabi: providing a definition of cheating, providing a definition of plagiarism, the importance of academic honesty, penalties for cheating, how to do proper citations, a web link to the honor code, indications about whether students can work together, and other instructions about the honor code. The average number of these topics included on a syllabus was a little over three (3.14), but that number significantly grew from the first to the second survey (2.9 topics to 3.37).

Other data acquired from the surveys were institutional demographic characteristics of the faculty respondents. Approximately half the respondents to both surveys had a long tenure of six or more years with the institution. In addition, roughly $25 \%$ of respondents were full professors, $25 \%$ associate_professors, 15\% full-time lecturers, with the remainder of the respondents being assistant professors. Between the two surveys, slightly less than half of the respondents were female (48\%), with slightly more than half of respondents on the second survey (53\%) being female. Thirteen percent of faculty respondents were in the business school.

\section{MODEL}

Because pre- and post-code survey results are available, it is possible to examine the relationships between observable characteristics and self-reported vigilance against cheating, as well as the change in those relationships following the implementation of a modified honor code. Because the surveys are anonymous, traditional panel techniques cannot be used. In addition, because respondents may be represented in both the pre- and post-code surveys, the use of a post-code binary variable interacted with other explanatory variables is inappropriate.

To avoid concerns about respondents being included in both pre- and post-code surveys, one could estimate a model for each survey and then compare the results. We use a similar approach. The two models can be simultaneously estimated by interacting each variable with a binary variable indicating whether the observation is from the pre-code survey, pre, or the post-code survey, post, and including binary variables for pre-code and post-code in place of the traditional constant. This method of interactions has the effect of estimating two separate regressions at the same time; it is equivalent to 
stacking the observations from each survey. The benefit of this method is that post-estimation comparison of the pre- and post-code coefficients is straightforward using an $F$ test. $^{\text {iv }}$

The following equation was estimated using ordinary-least squares for the model with prevention_index as the dependent variable and estimated using a Poisson regression with vigilance in detecting cheaters, vigilance, strictness of penalties, strict penalties, and vigilance in confronting suspected cheaters, confront, as the dependent variable.

$$
\begin{aligned}
& \text { Prevention_index }_{i}=\text { pre }_{i} x\left(\beta_{1}+\beta_{2} \text { code_on_syllabus }_{i}+\beta_{3} \text { topics }_{i}+\beta_{4} \text { discuss }_{i}+\Gamma \mathbf{X}\right)+\text { pre }_{i} \times\left(\beta_{13}+\right. \\
& \beta_{14} \text { code_on_syllabus }{ }_{i}+\beta_{15} \text { topics }_{i}+\beta_{16} \text { discuss } \\
& +
\end{aligned}
$$

Demographic variables are represented by $\boldsymbol{\Gamma}$ and $\boldsymbol{X}$, vectors of betas and demographic variables respectively. The regression results displayed in Table 4 list the pre- and post-code coefficients together for ease of discussion and comparison. In the model, topics is a quantitative variable, and the remainder of the explanatory variables are binary. All four dependent variables are quantitative to varying degrees and are scaled such that a higher value is consistent with a tougher stance on cheating.

The literature on observable characteristics of faculty who are soft or tough on cheating is relatively thin; thus, we have few priors about the coefficients of the variables in our analysis. We anticipate positive coefficients for code on syllabus, topics, and discuss as all of these reveal faculty attitudes toward cheating; those more concerned about cheating are likely to give it more weight on the syllabus and on the first (and possibly subsequent) day of class. We also anticipate full professor and long tenure are positively related to our measures of vigilance as older, more established professors presumably take more ownership in the institution and are beyond the more intense research pressures of younger faculty. ${ }^{v}$ However, two-tailed tests are used to assess the significance of each coefficient. We have no priors for associate professor or female.

\section{ESTIMATION RESULTS}

The estimation results are shown in Table 4. The first column in the table models the prevention index, constructed as the product of the number of items a faculty member considers to be cheating times numeric representations of their self-reported vigilance to detect cheating, strictness of penalties, and likelihood of confronting cheaters. Columns (2) through (4) model individual components of the index. The coefficients are ordered such that the estimated values for the pre-code and post-code regressions are adjacent to each other. Of note is a pattern of reduced significance and magnitude of the coefficients, lending support to the assertion that the implementation and increased emphasis of the honor code has made the faculty more uniform in their efforts toward preventing cheating.

While the faculty in general have become more engaged and uniform in their efforts to prevent cheating, some remain obstinate. For example, prior to the implementation of the new honor code, code_on_syllabus was not a significant signal of a faculty member's unobservable efforts to prevent cheating as measured by the prevention index in column (1). However, the inclusion of the honor code on the syllabus following the revision of the code is a strong signal of faculty members' prevention efforts and vigilance in confronting suspected cheaters. The large magnitude of the coefficient is less 
Table 4

Regression Results

\begin{tabular}{|c|c|c|c|c|}
\hline Dependent Variable & $\begin{array}{l}\text { (1) Prevention } \\
\text { Index }\end{array}$ & $\begin{array}{l}\text { (2) Detection } \\
\text { Vigilance }\end{array}$ & $\begin{array}{l}\text { (3) Strict } \\
\text { Penalties }\end{array}$ & $\begin{array}{l}\text { (4) Confront } \\
\text { Vigilance }\end{array}$ \\
\hline \multirow[t]{2}{*}{ code_on_syllabus_pre } & $-10.24^{+++}$ & $-0.0871^{*^{++}}$ & 0.00383 & $-0.0760^{++}$ \\
\hline & $(-1.16)$ & $(-1.67)$ & $(0.02)$ & $(-1.33)$ \\
\hline \multirow[t]{2}{*}{ code_on_syllabus_post } & $21.57^{* * * *^{+++}}$ & $0.136^{++}$ & 0.144 & $0.133^{* *^{++}}$ \\
\hline & (2.87) & $(1.55)$ & (1.10) & $(2.02)$ \\
\hline \multirow[t]{2}{*}{ topics_pre } & $6.671 * * *^{+}$ & $0.0298 * * *$ & $0.0703^{* * *++}$ & $0.0333 * * *$ \\
\hline & (4.38) & (3.95) & (4.03) & $(4.08)$ \\
\hline \multirow[t]{2}{*}{ topics_post } & $2.872^{*^{+}}$ & $0.0134^{*}$ & $0.0120^{++}$ & $0.0174 * 2$ \\
\hline & $(1.90)$ & (1.74) & $(0.73)$ & $(2.41)$ \\
\hline \multirow[t]{2}{*}{ discuss_pre } & $16.47^{* *^{+}}$ & $0.135 * * *^{++}$ & $0.259 * *$ & 0.0449 \\
\hline & $(2.52)$ & $(2.96)$ & $(2.14)$ & $(0.92)$ \\
\hline \multirow[t]{2}{*}{ discuss_post } & $-0.309^{+}$ & $-0.00196^{++}$ & 0.0251 & 0.00481 \\
\hline & $(-0.04)$ & $(-0.04)$ & $(0.25)$ & $(0.10)$ \\
\hline \multirow[t]{2}{*}{ female_pre } & 7.739 & 0.0439 & 0.101 & 0.0518 \\
\hline & (1.39) & $(1.41)$ & $(1.41)$ & $(1.54)$ \\
\hline \multirow[t]{2}{*}{ female_post } & 5.166 & 0.0131 & 0.0470 & 0.0245 \\
\hline & $(0.95)$ & $(0.41)$ & $(0.66)$ & $(0.77)$ \\
\hline \multirow[t]{2}{*}{ long_tenure_pre } & $16.78^{* * *}$ & -0.0193 & $0.217^{* *}$ & $0.0786 * *$ \\
\hline & $(2.60)$ & $(-0.52)$ & $(2.52)$ & (1.97) \\
\hline \multirow[t]{2}{*}{ long_tenure_post } & 10.71 & 0.0515 & 0.0559 & 0.0567 \\
\hline & $(1.40)$ & $(1.47)$ & $(0.64)$ & $(1.45)$ \\
\hline \multirow[t]{2}{*}{ full_professor_pre } & -1.678 & $0.0954^{* *++}$ & 0.0703 & 0.0467 \\
\hline & $(-0.20)$ & (2.07) & $(0.68)$ & $(0.98)$ \\
\hline \multirow[t]{2}{*}{ full_professor_post } & -11.57 & $-0.0483^{++}$ & -0.0347 & -0.00794 \\
\hline & $(-1.17)$ & $(-0.86)$ & $(-0.30)$ & $(-0.15)$ \\
\hline \multirow[t]{2}{*}{ associate_professor_pre } & $-23.44 * * *$ & -0.0218 & -0.126 & -0.0249 \\
\hline & $(-3.26)$ & $(-0.52)$ & $(-1.28)$ & $(-0.53)$ \\
\hline \multirow[t]{2}{*}{ associate_professor_post } & -9.069 & -0.00680 & -0.116 & -0.0456 \\
\hline & $(-1.18)$ & $(-0.19)$ & $(-1.18)$ & $(-1.04)$ \\
\hline \multirow[t]{2}{*}{ full_time_lec_pre } & 1.747 & 0.0366 & 0.0484 & -0.00250 \\
\hline & $(0.18)$ & $(0.76)$ & $(0.45)$ & $(-0.04)$ \\
\hline \multirow[t]{2}{*}{ full_time_lec_post } & 4.816 & 0.0357 & -0.0213 & 0.0563 \\
\hline & $(0.53)$ & $(0.77)$ & $(-0.21)$ & (1.29) \\
\hline \multirow[t]{2}{*}{ business_pre } & -6.009 & -0.0408 & -0.0429 & $-0.0856^{+}$ \\
\hline & $(-0.85)$ & $(-0.91)$ & $(-0.37)$ & $(-1.55)$ \\
\hline \multirow[t]{2}{*}{ business_post } & 7.390 & 0.0545 & 0.0432 & $0.0305^{+}$ \\
\hline & $(0.90)$ & $(1.22)$ & $(0.48)$ & $(0.88)$ \\
\hline \multirow[t]{2}{*}{ pre_code } & $34.57 * * *$ & $0.966 * * *$ & $-0.00126^{+}$ & $1.051^{* * *}$ \\
\hline & $(3.66)$ & $(16.45)$ & $(-0.01)$ & $(15.84)$ \\
\hline \multirow[t]{2}{*}{ post_code } & $30.37 * * *$ & $0.923 * * *$ & $0.403 * * *^{+}$ & $0.969 * * *$ \\
\hline & $(3.27)$ & $(9.68)$ & $(2.58)$ & $(13.17)$ \\
\hline$N$ & 427 & 427 & 427 & 427 \\
\hline$R^{2}$ & 0.761 & & & \\
\hline Pre $\neq$ post mode $P$-value & .0312 & .0561 & .0732 & .1758 \\
\hline $\begin{array}{l}\text { Note. } t \text { statistics in parenth } \\
{ }^{++} p<.05,{ }^{+++} p<.01\end{array}$ & $<0.1, * * p<0$ & ${ }^{*} p<0.01 ;$ dif & & ated by ${ }^{+} p<$ \\
\hline
\end{tabular}


reflective of faculty members who put the code on their syllabus and more indicative of the lax attitude of those who do not. On average, faculty members who include the code, and/or a link to it, on their syllabus have a higher prevention index, consider more behaviors to be cheating, consider themselves to be more vigilant in detecting cheating, assess their own penalties as strict, and believe themselves to be more likely to confront cheaters. ${ }^{\text {vi }}$ This difference is evidenced by the significantly larger coefficient estimates for the post- versus pre-code values in regressions (1), (2), and (4), all significantly different at the $5 \%$ level as evidenced by the two "plus" symbols next to the coefficient estimates.

Other indicators of faculty efforts such as topics are still an indicator but not as strong. The coefficient on topics remains a statistically significant indicator of faculty efforts in three of the four regressions but is a weaker signal following the implementation of the code. The pre- and post-code coefficients for topics are significantly different at the $10 \%$ level for (1), the $5 \%$ level in (3), and the $15 \%$ level for (2) and (4). The changes in these coefficients illustrate a substantial reduction in the difference between faculty in the visible front presented to students regarding academic dishonesty. Furthermore, discuss used to be a significant signal but no longer is; eighty-four percent (84\%) of faculty discuss academic honesty at the start of their courses. While this is not significantly more than before the survey, many of the faculty on the softer end of the enforcement spectrum now give academic honesty lip service in the classroom, thus reducing the value of the signal and increasing students' uncertainty about the likelihood of successfully cheating.

Females were slightly tougher than males, although not significantly so, but that gap has closed as well. Long-tenure has also lost its significance as a signal, again showing that gap between faculty members is closing. While associate professor previously indicated a weaker attitude toward detecting and penalizing cheating, associate professors are no longer distinguishable from assistant or full professors. Finally, there was also a culture shift in the business school. While business was not significantly weaker than other schools in a statistically significant sense, the estimated pre-code coefficients on business were negative in all four regressions, a finding consistent with the literature, including Meade (1992), McCabe and Trevino (1995), and Park (2003). However, the estimated post-code coefficients are positive, although still insignificant compared to other academic units at the university. For the regression examining vigilance in confronting cheaters, business is significantly more positive than the pre-code counterpart; the attitude toward preventing cheating within the business school has improved by more than attitudes in other academic units following the implementation of the modified honor code.

\section{CONCLUSION}

For all the efforts of administrators, reducing academic cheating is dependent on the faculty and students, and the students take their cues from the faculty. Faculty members are the front line in the fight against cheating, set the tone in the classroom, and give students their cues as to how tolerant they should be of fellow students' dishonesty. The research presented in this paper suggests that factors identifying softer faculty, such as the lack of an honor-code reference on their syllabus, not discussing academic honesty at the start of the course, and having the rank of associate professor, can be diminished in their signaling value by implementing a modified honor code to present a more unified 
faculty to students. There are several potential explanations for why some faculty members may be weaker on academic honesty than others, including ignorance of the university's policies, a lack of confidence in administrative support, and the desire to avoid uncomfortable confrontations with students among others. While we do not specifically identify the factors at play, our research does indicate that it is possible to overcome these qualms through stronger honor codes or policies and administrative support. The faculty is the front line in the fight against cheating, but administrative support is a necessary component in holding the line.

\section{REFERENCES}

Barnard-Brak, L., Schmidt, M., \& Wei, T. (2013). How effective is honor code reporting over instructorimplemented measures? A pilot study. Journal of College \& Character, 14(3), 231-240.

Becker, G. S. (1968). Crime and punishment: An economic approach. Journal of Political Economy, 76(2), 169-217.

Burrus, R. T., Jones, A. T., Sackley, W., \& Walker, M. (2013). It's the students stupid: How perceptions of student reporting impact cheating. The American Economist, 58(1), 51-59.

Burrus, R. T., McGoldrick, K., \& Schuhmann, P. (2007). Self-reports of student cheating: Does a definition of cheating matter? Journal of Economic Education, 38(1), 3-16.

Burton, B. K., \& Near, J. P. (1995). Estimating the incidence of wrongdoing and whistle-blowing: Results of a study using randomized response technique. Journal of Business Ethics, 14, 17-30.

Cochran, J. K., Chamlin, M. B., Wood, P. B., \& Sellers, C. S. (1999). Shame, embarrassment, and formal sanction threats: Extending the deterrence/rational choice model to academic dishonesty. Sociological Inquiry, 69(1), 91-105.

Connally v. General Construction Co., 269 US 385 (US Supreme Court January 4, 1926).

Coren, A. (2011). Turning a blind eye: Faculty who ignore student cheating. Journal of Academic Ethics, 9(4), 291-305.

Doob, A. N., \& Webster, C. M. (2003). Sentence severity and crime: Accepting the null hypothesis. Crime and Justice, 30, 143-195.

Gallant, T. B. (2007). The complexity of integrity culture change: A case study of a liberal arts college. The Review of Higher Education, 30(4), 391-411.

Graham, M. A., Monday, J., O'Brien, J., \& Steffen, S. (1994). Cheating at small colleges: An examination of student and faculty attitudes and behaviors. Journal of College Student Development, 35, 255260.

Higbee, J. L., \& Thomas, P. V. (2002). Student and faculty perceptions of behaviors that constitute cheating. NASPA Journal, 40(1), 39-52.

Hollinger, R. C., \& Lanza-Kaduce, L. (2009). Academic dishonesty and the perceived effectiveness of countermeasures: An empirical survey of cheating at a major public university. NASPA Journal, 46(4), 587-602. 
Jenkel, I., \& Haen, J. J. (2012). Influences on students' decisions to report cheating: A laboratory experiment. Journal of Academic Ethics, 10, 123-136.

LaSalle, R. E. (2009). The perception of detection, severity of punishment, and the probability of cheating. Journal of Forensic Studies in Accounting and Business, 1(2), 93-112.

McCabe, D. L., \& Trevino, L. K. (1993). Academic dishonesty: Honor codes and other contextual influences. Journal of Higher Education, 64(5), 522-538.

McCabe, D. L., \& Trevino, L. K. (1995). Cheating among business students: a challenge for business leaders and educators. Journal of Management Education, 19(2), 205-218.

McCabe, D. L., \& Trevino, L. K. (1997). Individual and contextual influences on academic dishonesty: A multicampus investigation. Research in Higher Education, 38(3), 379-396.

McCabe, D. L., Trevino, L. K., \& Butterfield, K. D. (2001). Dishonesty in academic environments: The influence of peer reporting requirements. Journal of Higher Education, 72(1), 29-45.

Meade, J. (1992). Cheating: Is academic dishonesty par for the course? Prism, 1(7), 30-32.

Mixon, F. G. (1996). Crime in the classroom: An extension. Journal of Economic Education, 27(3), 195200.

Nagin, D. S., \& Pogarsky, G. (2003). An experimental investigation of deterrence: Cheating, self-serving bias, and impulsivity. Criminology, 41(1), 167-194.

Nuss, E. M. (1984). Academic integrity: comparing faculty and student attitudes. Impriving College and University Teaching, 32(3), 140-144.

Ogilvie, J., \& Stewart, A. (2010). The integration of rational choice and self-efficacy theories: A situational analysis of student misconduct. Australian \& New Zealand Journal of Criminology, 43(1), 130155.

O'Rourke, J., Barnes, J., Deaton, A., Fulks, K., Ryan, K., \& Rettinger, D. A. (2010). Imitation is the sincerest form of cheating: The influence of direct knowledge and attitudes on academic dishonesty. Ethics and Behavior, 20(1), 47-64.

Parameswaran, A. (2007). Student dishonesty and faculty responsibility. Teaching in Higher Education, 12(2), 263-274.

Park, C. (2003). In other (people's) words: Plagiarism by university students--literature and lessons. Assessment \& Evaluation in Higher Education, 28(5), 471-488.

Paternoster, R. (1987). The deterrent effect of the perceived certainty and severity of punishment: A review of the evidence and issues. Justice Quarterly, 4(2), 173-217.

Rennie, S. C., \& Crosby, J. R. (2002). Students' perceptions of whistle blowing: Implications for selfregulation. A questionnaire and focus group survey. Medical Education, 36, 173-179.

Roig, M., \& Ballew, C. (1994). Attitudes toward cheating of self and others by college students and professors. The Psychological Record, 44, 3-12. 
Roth, N. L., \& McCabe, D. L. (1995). Communication strategies for addressing academic dishonesty. Journal of College Student Development, 36(6), 531-541.

Sierles, F. S., Kushner, B. D., \& Krause, P. B. (1988). A controlled experiment with a medical student honor system. Journal of Medical Education, 63, 705-712.

Staats, S., Hupp, J. M., Wallace, H., \& Greley, J. (2009). Heroes don't cheat: An examination of academic dishonesty and students' views on why professors don't report cheating. Ethics \& Behavior, 19(3), 171-183.

Vandehey, M., Diekhoff, G., \& LaBeff, E. (2007). College cheating: A twenty-year follow-up and the addition of an honor code. Journal of College Student Development, 48(4), 468-480.

Whitley, B. E., \& Keith-Spiegel, P. (2001). Academic integrity as an institutional issue. Ethics and Behavior, 11(3), 325-342.

ABOUT THE AUTHORS

Robert T. Burrus Jr., Ph.D. (burrusr@uncw.edu), is the Interim Dean of the Cameron School of Business at the University of North Carolina Wilmington where he has studied academic dishonesty within the economics major and campus wide. As Chair of the economics department Dr. Burrus was instrumental in helping UNCW rework its honor code. In addition to his duties as Dean, Dr. Burrus also helps to coordinate the Teaching Economics Workshop at Wrightsville Beach for the last 14 years.

Adam T. Jones, Ph.D. (jonesat@uncw.edu), is Assistant Professor of Economics at the University of North Carolina Wilmington. Prior to pursing his PhD in economics, Dr. Jones was the Director of Economic Development with the Covington/Newton County Chamber of Commerce in Covington, GA. In addition to his research on urban and regional economics Dr. Jones has spent considerable time researching academic dishonesty and the results of different pedagogies.

William H. Sackley, Ph.D. (sackleyw@uncw.edu), is Professor of Finance at the University of North Carolina Wilmington. Dr. Sackley has been a professor of Finance at CSB since 1999 and served as Director for the Swain Center for Business and Economics Services until August 2013. Prior to joining the faculty, he was a Professor at the University of Southern Mississippi. He was awarded the Chartered Financial Analyst (CFA) designation in 1996.

Michael Walker, Ph.D. (walker@uncw.edu), is Dean of Students at the University of North Carolina Wilmington. Dr. Walker is responsible for management and leadership of the Campus Conduct, the Honor Code, Fraternity \& Sorority Life, Case Management, and services for non-traditional/adult learners, campus recreation, office of student leadership and engagement, and campus life.

Please address correspondence to Adam Jones, 601 S. College Rd., Wilmington, NC, 28403-5945. Phone: (910) 962-2539 
i This raises the question of whether many institution's policies would meet the Justice Sutherlands vagueness doctrine suggesting vague laws are void (Connally v. General Construction Co., 1926).

ii See Burrus, Jones, Sackley and Walker (2013), McCabe and Trevino (1993), and Mixon (1996) among others.

iii The Chronbach's alpha statistic of reliability for the index is 0.641 , slightly below the commonly accepted 0.70 rule of thumb. However, the small number of items in the index, four, deflates the value such that 0.641 is assumed to indicate a reliable index.

iv Alternatively the regressions could be estimated separately and a Chow test used to compare coefficients. However, separate regressions do not allow for simple testing of individual coefficients to see if the specific coefficients have changed.

${ }^{v}$ Our grandfathers were pessimistic about younger generations, so we assume this comes with age!

vi These comparisons are made looking only at sample means and are not tested for significance of differences. 